Article

\title{
Synergic Sustainability Implications of Additive Manufacturing in Automotive Spare Parts: A Case Analysis
}

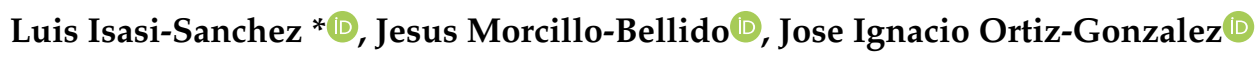 \\ and Alfonso Duran-Heras \\ EPS. Área de Ingeniería de Organización, Universidad Carlos III de Madrid, 28911 Leganés, Spain; \\ morcillo@ing.uc3m.es (J.M.-B.); joortiz@ing.uc3m.es (J.I.O.-G.); duran@ing.uc3m.es (A.D.-H.) \\ * Correspondence: lisasi@ing.uc3m.es; Tel.: +34-91-624-8766
}

Received: 15 September 2020; Accepted: 9 October 2020; Published: 14 October 2020

\begin{abstract}
Triple bottom line (3BL) approaches to sustainable supply chain management (SSCM) often involve trade-offs between their three dimensions (economic, environmental, and social), thus curtailing its application and leading to goal unalignment among stakeholders. Under some circumstances, however, synergic approaches (typically involving disruptive innovations) might allow simultaneous improvement in one or more dimensions without compromising the others. This paper analyzes one such case: the potential of properly designed additive manufacturing approaches in the automotive spare parts industry to simultaneously boost profits and reduce environmental impact. It is based on the systematic analysis of the real spare parts business of a mid-size automotive brand in Spain. Its results suggest that such synergic, self-reinforcing opportunities do indeed exist, and might even be further developed by strategically integrating sustainability constituents such as circularity.
\end{abstract}

Keywords: additive manufacturing; disruption; sustainable supply chain management (SSCM); spare parts; automotive industry; business model

\section{Introduction}

Nowadays, the industrial and manufacturing sector is immersed in a real revolution, whose various constituents have been grouped under the umbrella concept " 4.0 Industry" [1]. The main characteristics of this concept are the massive use of processes' acquired data and the use of cyber physical system, that were unthinkable just a few years ago. As a fundamental part of the necessary framework for the development of the above mentioned 4.0 Industry concept, additive manufacturing (AM) is becoming increasingly relevant, as the research activities in new metallic materials, printing processes, simulation and optimization techniques, and algorithms have been endlessly growing. Therefore, AM is likely to be fully incorporated in industrial processes in the near future. Some authors have extensively studied this exponential development in recent years [2,3]. In today's social environment, not only are the economic and industrial aspects important, but it is also key to consider social changes and impacts, mainly with regard to health and safety [4]. Amid this growing awareness of aspects such as sustainability and energy efficiency, AM offers the possibility of forming parts with exactly the required shape and material, without any waste [5].

There is still no global consensus on the level of savings, sales increases, and impact on other key performance indicators (KPIs) that applying AM to industrial processes might bring about. However, most estimations of the potential impact of AM in the car industry conclude that it could lead to savings of up to $23-25 \%$ of production costs in the near future, and could also enable up to $8-11 \%$ of additional business volume from products and services not offered so far [6]. 
The automotive sector currently encompasses a small number of large worldwide manufacturing groups. These groups typically have a global presence, both geographically and in terms of product range; this allows them to diversify and capitalize on important synergies in their activities. As competition increases and mobility needs evolve around the world, the turnover and industrial margin of the main players in the automotive sector continue to decrease. This forces them to explore strategic alternatives that could increase their synergies and, consequently, improve their competitiveness. Furthermore, optimization of the structure of production costs requires cooperation between all the involved stakeholders [7], even including some that up to now were not involved in this sector, such as AM providers. Given the acceleration in these changes (regarding customers, mobility, production, laws, etc.), and the emergence of key new players in the automotive sector, it is imperative not to allocate resources to develop technologies that are not going to be dominant [8].

One of the fundamental pillars of the current business model in the automotive industry is undoubtedly the business known as after-sales [9], as it represents the main source of profit for both local distributors and the manufacturers themselves. Nevertheless, it was not until the end of the 20th century, or even the beginning of the 21st, that "industrial" applications of AM were found in after-sales, such as the Request For Proposals of the American army to supply parts for its aircraft fleet [10] and the subsequent development of the project [11].

In the automotive industry, the level of competition is much higher than in the aeronautical sector, and so is the worldwide business volume. Therefore, this paper aims to analyze the impact of using AM as an alternative for the production of the spare parts on various KPIs, as well as the main operational implications. It takes a holistic point of view, encompassing the three main dimensions of sustainable supply chain management (SSCM), namely economic, environmental, and social. It focuses on the spare parts used by a mid-size car brand in its after-sales activities in Spain, including all the origin countries of the analyzed parts (Figure 1). The analyzed data correspond to the real sales of spare parts of a mid-size automotive brand in Spain (average running fleet of that brand: 72,306 vehicles) during a one-year period (from July 2018 until July 2019). In order to obtain relevant conclusions, the whole process, from the manufacturing plants to the retailer operations, has been taking into consideration.

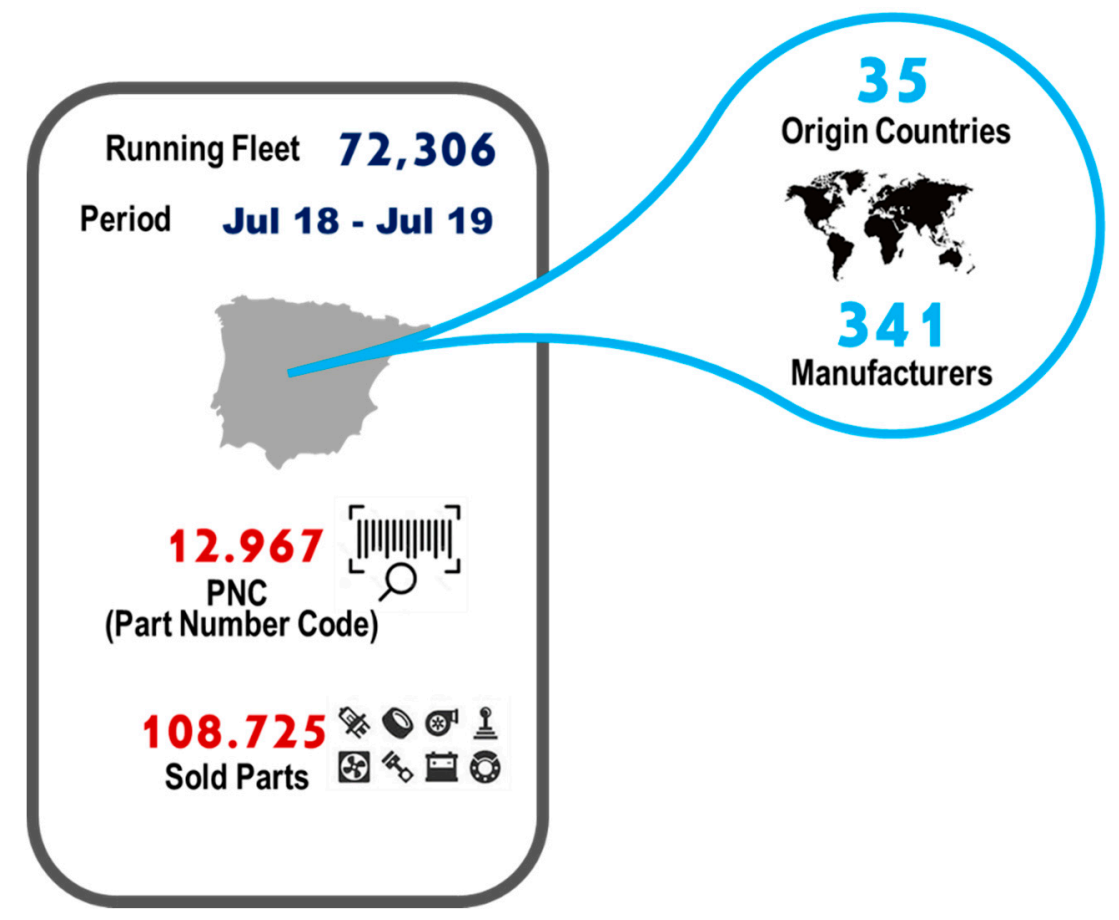

Figure 1. Analyzed case. 
The main currently available AM techniques, namely multi jet fusion (MJF), selective laser sintering (SLS), stereolithography (SLA), material jetting (MJ), and digital light processing (DLP), and their foreseeable future evolution have been considered.

As mentioned before, a global consensus is far for being achieved regarding how the AM techniques are going to evolve, what the impact will be in the various industrial sectors, and when and up to what extent will the main players within each sector react and really implement AM processes in their value chains. However, the potential impact of AM on the different business models and their respective value chains is so substantial, that there is no single industrial activity that is not reflecting about potential synergies and process improvements.

Introducing AM would affect not just manufacturing activities, but also logistic and strategical aspects; thus, this alternative should be analyzed from a holistic and global perspective. Interesting analyses of the trends and possible evolution of additive manufacturing technologies and their potential impact on industry can be found in [8], [12], or [13].

It should be emphasized that, before any industrial application of AM can be launched in an environment such as the automobile parts' supply chain, an in-depth analysis of the risks that would be faced must be carried out. Two of these risks stand out as particularly critical for business: intellectual property management and liability. The final design of a particular component or system entails significant costs (development, prototyping, testing, re-engineering, etc.) that are protected, up to some extent, by intellectual property. Therefore, it is an asset that should be carefully managed and protected. Civil and/or criminal liability is also a key issue for automotive manufacturers. The failure of any critical component during the service of the car in which it had been installed would have very serious consequences, both economical and image related. An in-depth assessment of these risks is beyond the scope of this paper, but an appropriate analysis can be found in several studies [14-16].

\section{Research Gap and Objectives}

\subsection{Research Gap}

As discussed in the previous section, the technical aspects of AM have been extensively researched. Furthermore, amid a growing realization of the multidimensional nature of AM's impacts, an incipient body of scientific publications such as [4,17-19] delve into its potential implications for business models. They tend, however, to restrict themselves to narrowly defined areas; the study reported in [17] reaches significant and current conclusions; however, they are confined to only rapid prototyping; [19] performs an interesting analysis on sustainable aspects of AM but only related to small and medium enterprises (SME), and is based on the analysis of a small set of parts; [4] mainly concentrates on social changes caused or derived from the use of AM techniques inside the industry. What seems to be lacking is a holistic, encompassing analysis of the overall applicability of the various AM techniques to a relevant industry.

Heightened competition within the automotive sector, in addition to its sheer business volume and strategic economic, environmental, and social significance, suggests it might be a fertile ground for exploring AM's holistic potential. However, given AM's current level of development, it is still ill-prepared for the mass production sections of the automotive sector's supply chain. The aftersales/spare parts business, on the other hand, stands out as a promising candidate area.

There is, however, a scarcity of published research on AM's potential for transforming the after-sales business. Furthermore, existing literature on AM's business potentiality (in all sectors) lacks specific financial analysis of AM's foreseeable impact on the economic bottom line, maybe due to the fact that firms tend to closely guard their internal economic data, specifically the detailed cost breakdown that would be required for such an analysis. Triple bottom line sustainability analysis is consequently impaired, as its viability is contingent on attaining financial sufficiency. 
This is the dual research gap that this paper aims to address: lack of real data based specific, KPI-oriented analysis of AM's holistic potential, and specifically the uncharted territory of AM's applicability to the transformation of the automotive sector's after-sales business.

\subsection{Objectives}

Consequently, the primary objective of this research is to analyze, for the specific case of the spare parts being considered, the potential quantitative (KPI-based) and qualitative (business and organizational model transformation) economic, social, and environmental impacts of switching the current manufacturing processes from the current approaches to those based on AM techniques. This main objective naturally unfolds into two secondary objectives. By exploiting a representative set of real data that is normally hard to access for research purposes, it aims at providing practicing managers with a reality check that complements existing theoretical analyses, in order to spearhead change. Additionally, as the data comes from the automotive sector's after-sales business, the second secondary objective is to shed light into this hitherto insufficiently scrutinized area that appears to be AM's most promising entry point into the strategic automotive industry.

This research will complement and extend previously published studies by focusing both on the financial impact of these changes for the automotive brand and on the potential benefits for the society that such approach would entail, from a sustainability point of view.

It is clear that, even though they belong to the same industrial sector, the idiosyncrasy and reality of each individual automotive company is different from that of the other players, as illustrated by their specific traits (geographical distribution of sales and manufacturing activities, production volumes, etc.) However, the results of this research could help any of them (as well as, hopefully, companies from other industries) to systematically analyze the potential application of AM to their value chains and, consequently, to evaluate the associated impact on their business, not merely from a "bottom line" approach, but also from a more global and social perspective.

\section{Materials and Methods}

\subsection{Overview}

In order to achieve these objectives, an appropriate materials and methods design was adopted, as explained in the following sections. A summary overview is presented below.

Within the automotive sector's after-sales business, chosen here as a representative case, the implementation of AM would radically transform the very structure of the supply chain, with substantial sustainability implications. Private firms, however, will only adopt AM if it is economically justified. This research aims to evaluate if appropriately implemented AM would actually improve various KPIs at a relevant manufacturer that has granted authors access to relevant data for research purposes. The analysis focuses on spare parts sold for maintenance.

Not all spare parts are currently appropriate candidates for AM; hence, the applicable subset was firstly identified. Having thus delimited the scope of the business that would be affected, and therefore its current economic volume, AM's impact on relevant KPIs was analyzed. Given the prevailing level of competition, it is argued that such a move would not significantly affect either sales volumes or selling prices. Thus, eventual impact on profitability would basically derive from cost reductions, i.e., from the difference between costs being currently accrued by the manufacturer in the production of these parts through the existing processes and their foreseeable cost using AM techniques for their forming processes. Detailed per part cost data for existing processes was provided by the manufacturer under confidentiality agreement. Per part costs using AM were estimated through a cost model, proposed in this paper, that considers both part traits and characteristics of the specific applicable AM technique. This cost model was parameterized and validated through the prices obtained, for various parts, in requests for quotation (RFQs) sent to recognized European providers of AM parts. 
Per-part cost reduction estimates thus obtained were then weighted by their current relative sales volumes to calculate their impact on various KPIs. Having thus established the economic viability of the approach, the transformation it would entail of the industry's SC and the ensuing sustainability implications were then analyzed. A key element of this SC transformation would be the demise of the traditional concept of supplier, which would be replaced by a platform-enabled (AM hub) network of suppliers among which orders would be dynamically allocated depending on spare capacity. The sustainability implications would include the localization of production ("re-shoring"), thus reducing transportation, and the avoidance of service-related stocks of spare parts.

At this point, it is clear that the evolution of the SCM model towards a distributed or decentralized SSCM model, which is imperative to achieve a circular economy, is critical to analyze all the impacts, as every single decision influences costs, emissions, delivery times, and service levels [20], and not just during the manufacturing process, but throughout the whole life cycle [21].

\subsection{Research Data}

Among the total parts' sales in the period being analyzed, only those that could be manufactured using AM techniques were compared in terms of alternative manufacturing costs. The selection criteria, taking into consideration the current technologies and situation, are described below.

1. Is it possible to directly manufacture the part through the AM process? Not all the parts being sold in the after-sales activities of a brand can be formed through AM. For example, the various assemblies (such as short block, complete gearbox, or engine the normalized parts (such bolts, bearings, and clips), as well as some specific and complex parts (such as cylinder head gasket, pistons, and frame beams) were not considered.

2. Is it worthwhile to manufacture the parts using AM? Based on the authors' former experience, the parts that were considered potential candidates for AM manufacturing processes were those with low production difficulty as well as limited sales (in this case study). The main reasons for this criterium are firstly, that the cost associated with additive manufacturing is generally lower the simpler the part is to manufacture, and secondly, in the current "conventional" distribution model, the lower the sales volume and the more distributed the final customers, the higher the associated unitary SCM costs.

3. For those parts that could be formed using AM techniques, and whose production process using AM was considered worthwhile, which would be the most appropriate AM technique? For each component, the specific AM technique that best suits its manufacturing process depends on its inherent characteristics (shape, material, size, etc.). The resulting breakdown for the parts being considered parts, based on the experience of the authors, is shown in Figure 2.

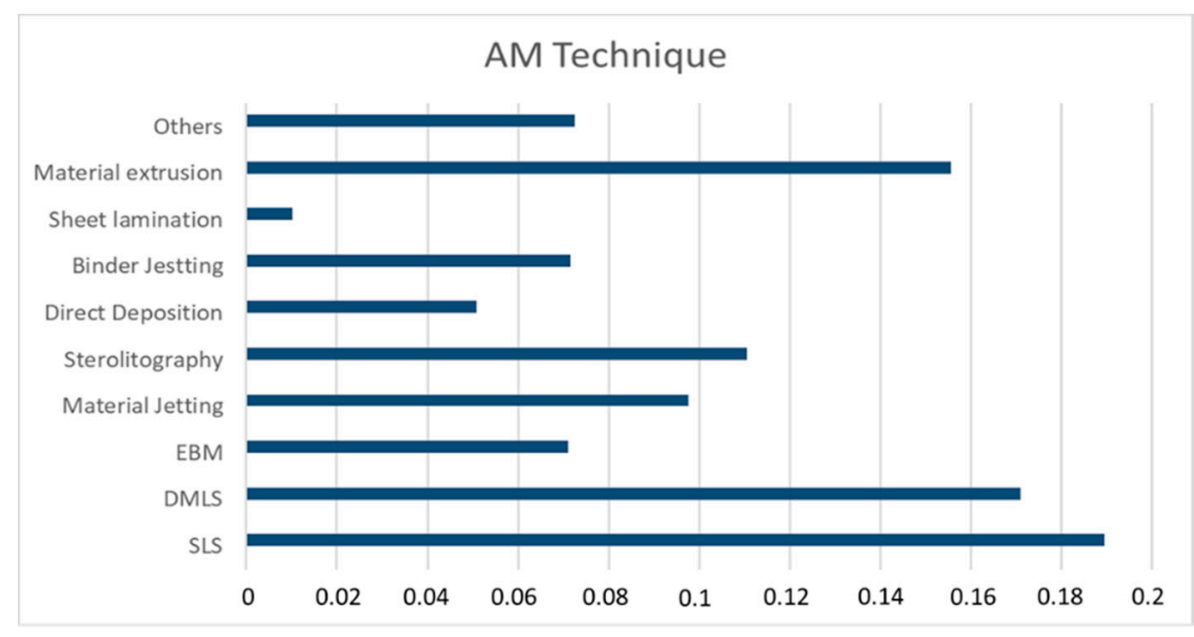

Figure 2. Appropriate AM technique breakdown for the parts being considered. 
4. Cost estimation model. One of the main premises of the proposed model was simplicity, as it had to be systematically and easily applicable to a significant number of parts. Thus, the main objective of the present work was not to "overfit" the adjustment of the model to the available data, particularly considering the large number of different parts and the fact that it is a multi-variable problem. The key goal was to reach general but interesting conclusions, thus enabling other manufacturers to start evaluating the potentiality of AM application within their business models. Based on these premises, the proposed formulation was as follows:

$$
E \operatorname{Cos} t=(V * \rho) * M C+f_{c p} *\left(\frac{V * \rho}{F S i}\right) * h_{r i}
$$

where:

ECost $=$ Estimated cost if manufactured using AM technologies

Part parameters are:

$V=$ Volume

$\rho=$ Density

$f_{c p}=$ Complexity factor of the part

AM Technology parameters (each " $\mathrm{i}$ " sub index represent one AM Technology) are:

$M C=$ Material cost

$F S_{i}=$ Forming Speed of " $i$ " AM Technology

$h_{r i}=$ Hourly rate of operating machine for " $i$ " AM Technology

5. Cost model validation. The specific values of the parameters that were finally used in the estimation are not reported in this paper due to confidentiality agreements that only allow the publication of aggregated results and conclusions. Nevertheless, the proposed model was validated through price quotations sent to recognized European providers of AM parts. Specifically, requests for quotations of representative parts were sent to GPI, Materialise, AMFG, Markforged, SSEB, Additive 3D, Initial, and Weerg. In order to have better estimations, only those parts for which at least two offers were received were considered for the study. The following data provides some insights into the reliability and precision of the cost estimation:

- Quotations on the same parts, coming from different suppliers, showed on average a $6 \%$ difference (between maximum and minimum received prices); the highest recorded difference was $26 \%$.

- When quotes for similar parts were received from the same supplier, with time intervals greater than four weeks, sometimes the prices varied significantly. When inquiring about the cause of these variations, two reasons were frequently mentioned: changes in the occupation rate of the machines and fluctuations in the cost of materials.

- The deviation observed between the cost estimation while using AM techniques, calculated through the proposed model, and the real offers received from the different suppliers, ranged from $4.3 \%$ to $16.2 \%$.

\subsection{Current SCM Model}

The SCM scheme used in the distribution of the spare parts discussed in this paper, which is also currently being used by most automobile groups, is summarized in Figure 3, depicting in a graphic and schematic way the process from the manufacturers to the final customers. In this case study, 341 different suppliers manufacture the parts that, in the period being considered, were sold in Spain for this brand. Most of them supply parts directly to the production plants for the manufacturing of cars and subassemblies (like engines, gearboxes, uprights, etc.). They also supply parts to the central warehouses, usually known as regional distribution centers, from where the authorized dealers and independent service points are supplied. During the last years, direct sales through internet must also be considered (bottom part of the figure), although they are not relevant for the present analysis $[9,22]$. 


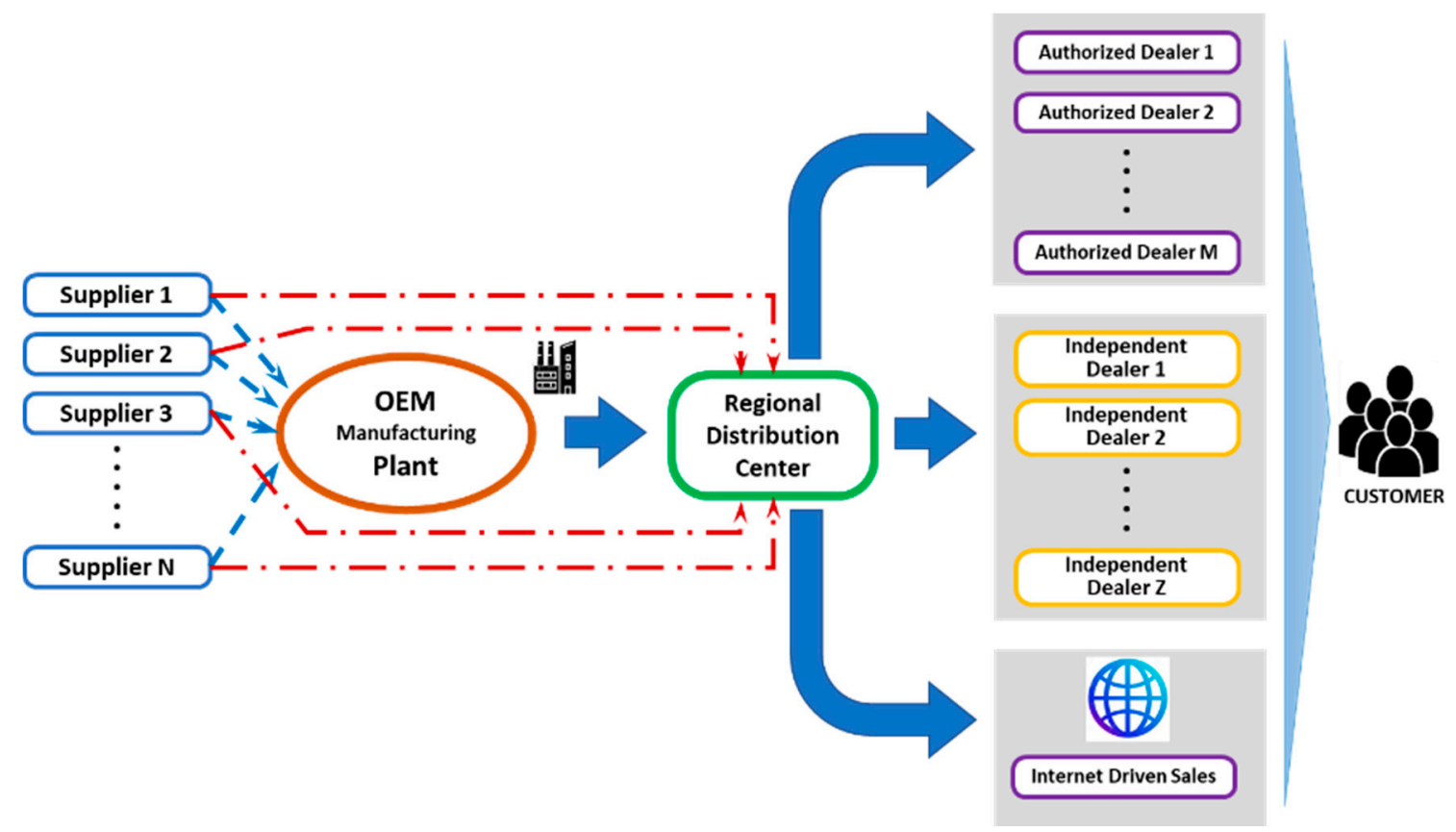

Figure 3. Summarized schema of parts distribution SCM used nowadays in automotive sector.

Two key aspects to be taken into account when trying to extrapolate the conclusions of the present research to other brands or markets are the evolution of the AM techniques and the information flow and its analysis. As available AM technologies advance, the processing time, post-processing operations and cost of both the required hardware and raw materials plunge, thus adding to the appeal of abandoning "traditional" forming processes. Additionally, the growing capabilities that the adoption of what is called 4.0 Industry are gradually enabling will boost the capability to analyze relevant information. This will in turn allow a significant reduction in time to market and boost customer service quality, as described in [3] and more recently in [23].

The analysis of this current distribution model allows the estimation of the current cost for the parts, which is essentially arrived at by adding the cost of raw materials, the total cost of production processes (casting, forming, stamping, milling, touring, etc.), and all the operational and logistic expense items (mainly transport, financial, and insurances-covering various risks, pecuniary losses, and also exchange-rate risks).

In this case study, all these data were provided by the analyzed brand (obviously with the compromise of protecting the detailed data and only distributing aggregate conclusions). It is nevertheless worth highlighting that large automotive companies, which manufacture enormous series, generally attain real costs that are well below estimations through theoretical calculations like those described in [24].

These manufacturing costs for the various parts can then be compared with their ESRP (European suggested retail price) to assess the gross margin. It is important to highlight that these ESRPs are not directly derived from the manufacturing and operational costs, as the brands must also consider strategic aspects. For example, the retail prices of those parts normally referred to as "fast moving parts", such as brake pads and discs and air and oil filters, which have low complexity and high sales volumes, are much closer to the actual production cost, due to competition from independent suppliers. Price spread is significantly higher in more complex parts requiring specific technologies (such as cylinder heads and casings), normally referred to as "captive", for which there is no real competition.

Apart from this main factor, most of the brands set different price policies depending on who the customer is that is eventually going to pay for the parts. For instance, they might have specific pricing approaches for some parts like bumpers, doors, windscreens, and locks, whose costs are often 
covered by insurance companies, particularly for new cars-less than four years old-which normally subscribe to full coverage insurance policies [9].

\subsection{AM-based Supply Chain Model}

Once the use of additive manufacturing is considered, the characteristics of most manufacturing systems and processes can be seriously affected. Although it is still difficult to predict how, when, and up to what extent is AM going to affect the business models, it seems to be widely accepted that it will have a very important impact, whatever the industrial sector and whichever the stakeholder being considered. Some very good analyses can be found in [25] for end users, [26] for the medical sector, [27] for general industrial activities, or [11] for the aeronautical field. In the automotive spare parts sector, and for the case study that is presented in this paper, the utilization of AM manufacturing technologies would allow, for those parts, the implementation of a new distribution model such as the one schematically shown in Figure 4.

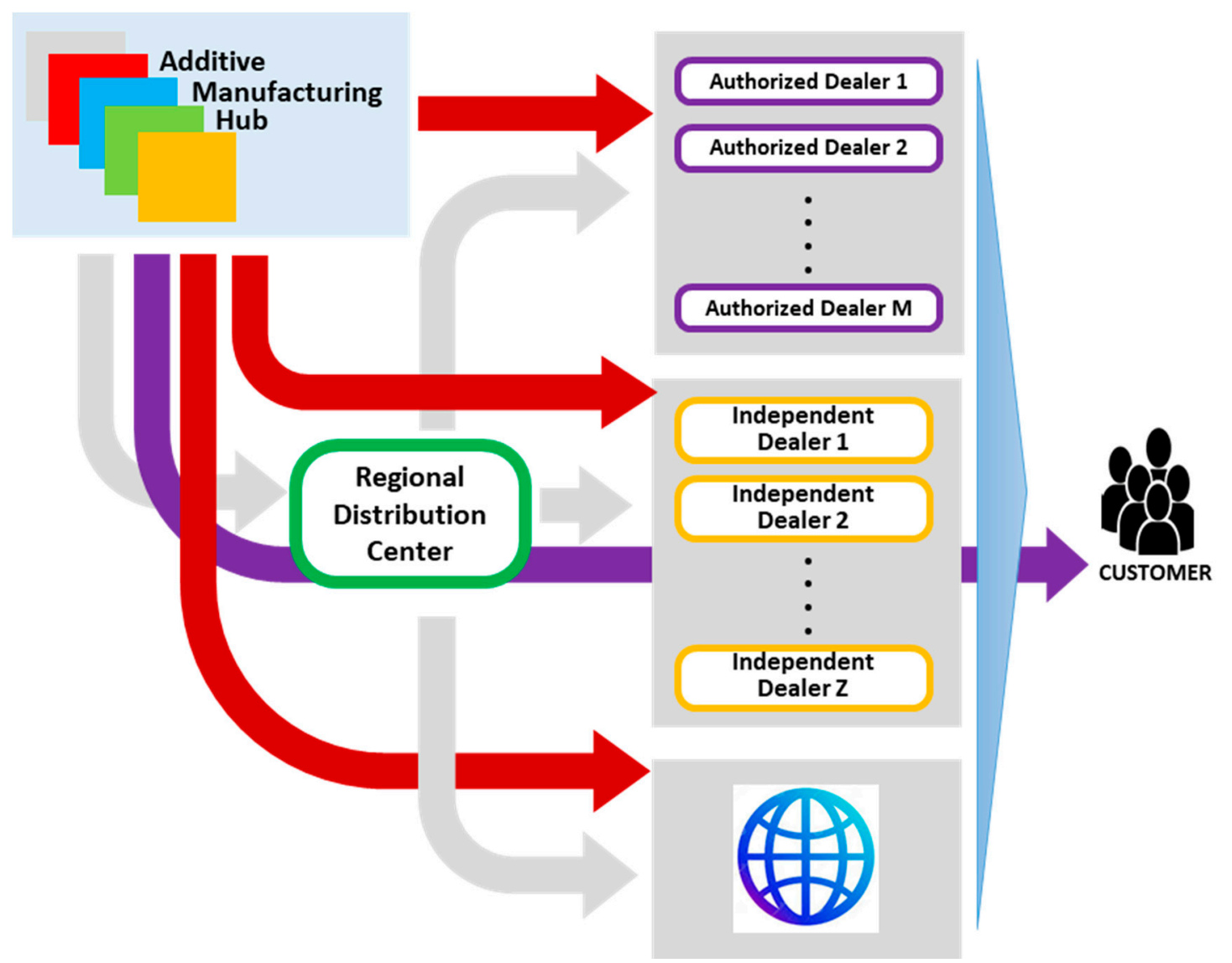

Figure 4. Summarized schema of parts distribution SCM for automotive sector, when using additive manufacturing.

One of the main differences between the "traditional" distribution model (Figure 3) and the one presented in Figure 4 is the source of the parts. While as in the former case the suppliers are, at least for the contract period, always the same for the same parts, in the new distribution model, the suppliers for the parts would be organized into one or several "AM hubs". These "AM hubs" would be automated, centralized platforms that would steer and redirect the formal orders to the available 3D machines, normally owned by separate firms, thus operating with a distributed manufacturing base. It is likely that many readers of this paper have ordered some AM parts in the past themselves, from one or several of the well-known manufacturing platforms or companies. If so, they may have realized that the ordered parts, even those with the same characteristics, do not always come from the same final 
manufacturers. These final manufacturers are often very specialized small and medium enterprises (SMEs), focused solely on that particular technique, that are thus able to attain an unbeatable level of efficiency.

Even after implementing this new spare parts manufacturing and distribution model, in the short and medium term, most of the parts being sold would still be manufactured with "conventional" processes, as the costs would be lower than by applying AM. This would be particularly marked for long manufacturing series.

As shown in Figure 4, a great variety of commercial transactions and flows appear, as the whole business becomes more decentralized. Additionally, some other possibilities (that are not going to be considered in the present paper in order to simplify the process as much as possible) could quite easily appear. Some of them could be:

- Real price competition for the orders being placed if different members of the hub could compete depending on their current level of activity, available capacity, etc.

- Regional Distribution Centers incorporation of repairing and/or assembling and/or packaging capabilities for certain parts.

- Different policies regarding "free ordering parts" and "captive ones", depending on technology agreements, etc.

- Integration of the recycled parts coming from the authorized centers for end-of-life vehicles' treatment.

As it is the case in other fast-moving consumer platforms like Amazon, AliExpress, etc., with this new model, the relationship between all the stakeholders becomes much more flexible and open. The main technological aspect that makes this possible is the versatility of the 3D machines. In a traditional forming process, the machines and tools being used should be prepared and adjusted for each part. However, when using AM, it is possible to manufacture, with the same 3D printer, completely different parts, just by loading a different computer file. This is akin to printing different documents in a normal printer, without setting it up, as it was imperative some decades ago when printing presses were used.

In the "traditional" business model, the final customer is supplied directly from the dealers, which are in turn supplied by the regional distribution center, as no one else is capable of placing orders to the original parts' suppliers. However, in the proposed model (Figure 4), the final customer could be directly supplied by nearly all the stakeholders (authorized dealers, independent dealers, the manufacturer, etc.), and could eventually place the order by himself. There are three main possible flows for the spare parts:

- Red arrows: The AM Hub, after having received the order, and distributed it to the most convenient final manufacturer in that particular moment, sends and invoices directly the part to the dealers (both independent and authorized), who finally provide the service to the final customer.

- Grey arrows: like in the traditional model, but with the parts coming from the AM hubs, instead of from the traditional suppliers.

- Violet arrow: The customer orders the part directly from the AM provider.

Some important differences arise from this AM model. First, it would decentralize production, making it easier for any supplier specialized in additive manufacturing to manufacture parts from the original drawings or even from the scan of the real part. Undoubtedly, this would entail other problems (intellectual property, etc.), but their analysis is not within the scope of this work. Furthermore, the traditional concept of supplier, which is traditionally associated with a marked character of exclusive supply and distribution, would be replaced by a network of suppliers that could manufacture the parts or not, depending on the availability of their machines. When the supply chain is long, and a good customer service is required, the management of the different stocks along all the stages (OEM, manufacturer, regional centers, distributors, etc.), becomes critical. Finally, it would no longer 
make sense to transport the parts from other continents, significantly reducing logistic costs and pollutant emissions.

Additionally, it should also be noted that, in recent years, the ease for the end customer to find components via internet, and the implementation at the European level of the new distribution regulation [28], is generating a loss of income in the spare parts business of automotive groups [9,29]. To compensate for this loss, they are adopting new business models that attempt to complement the traditional ones (maintenance contracts, mobility services, etc.).

\subsection{Cost Comparison}

The automotive sector is one of the most competitive ones among the industrial activities. Therefore, incumbents have limited market power and could be considered as "price takers". As a consequence, the ESRPs, which are the "market" prices for the parts, could be considered as fixed for a given moment and situation. As already mentioned in former sections, the brands fix the retail prices for their spare parts, depending on their policies and strategy, to balance demand and offer while keeping a good business return. If ESRPs remain constant, the only degree of freedom to evaluate the margin of the spare parts for the brand is their cost.

Nevertheless, at this point it is important to highlight the hypotheses that have been considered to carry out this work:

- As the introduction of AM techniques to produce spare parts will lead to a surge in competition among suppliers, prices could be expected to change. However, this is not being considered in this analysis.

- Sales volumes for the spare parts being analyzed are considered unchanged, even though the introduction of cheaper production methods, along with the steep reduction in delivery times, could be expected to boost sales.

To carry out the economic analysis, the following two costs are obtained for each of the parts being studied:

- Part cost under the current production model: can be directly calculated from the ESRP (known from the public price list of the brand), deducting the commercial margin (not publicly available, but supplied by the brand for this particular case study).

- Part cost under AM-based model: calculated as previously described through the cost estimation model. Figure 5 shows the simplified schema that has been used for the cost comparison.

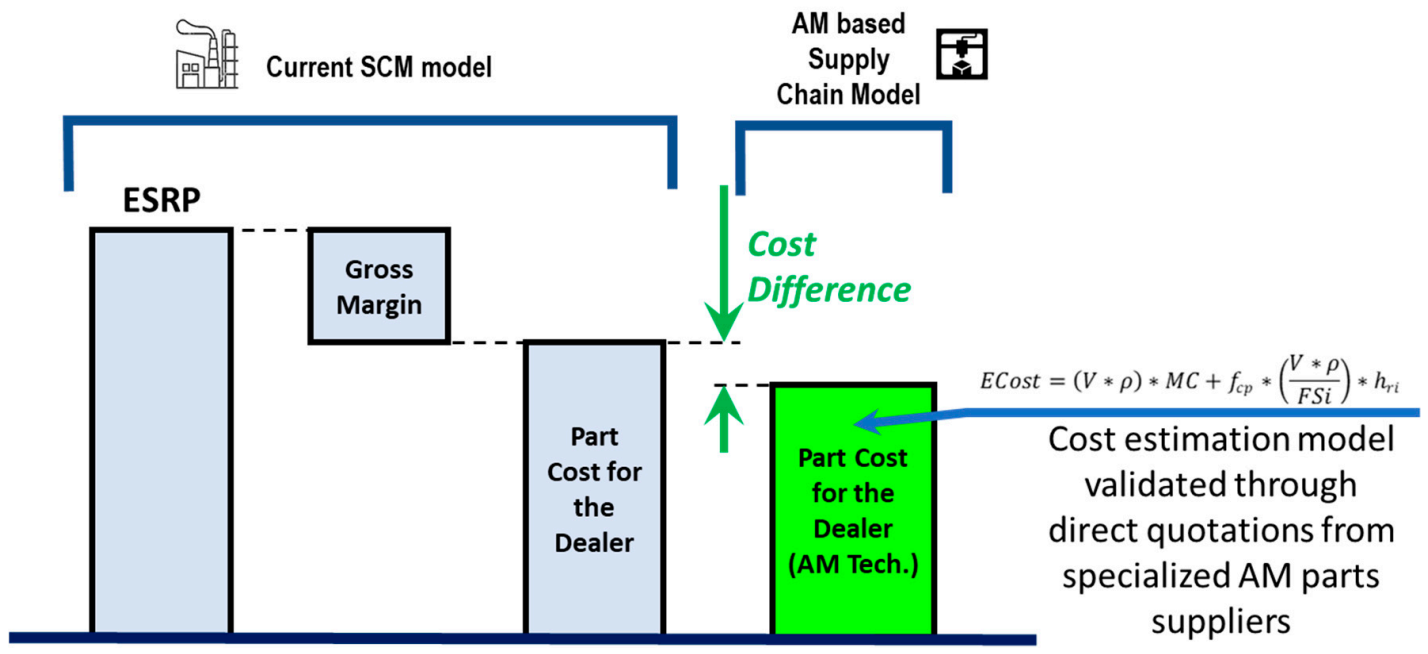

Figure 5. Simplified schema of parts' cost comparison. 
Out of the total sales analyzed (108,725 pieces corresponding to a total of 12,967 PNCs), the cost analysis in the case study has been applied to a total of 6680 pieces, belonging to a total of 2662 PNCs, and to the corresponding 247 PNC families. The difference between PNC and PNC family is clear for automotive sector workers and can be graphically explained with an example to all those that are not familiar with it. For instance, when thinking about a front bumper of a specific model that would correspond to a specific PNC, that PNC would include all the specific references of all the different bumpers of the different versions of that model. Additionally, the PNC family would correspond to all the bumpers, not only for all the versions of that particular model, but for all the bumpers for all the versions and all the models. This means that a PNC family integrates a lot of similar parts, which have important common traits regarding commercial policy, average size, materials, cost, categorization, and, obviously, manufacturing characteristics.

The independent variables that have been used for the cost model that is proposed in the present work have already been described. The main aspects being considered are size and volume of the component, material, density, AM technology to be applied, and shape difficulty.

In most AM related studies and research publications $[2,13,30]$, the classification of the parts based on the dimensions of the components is quite consistent, although unfortunately not fully normalized. The classification that has been used for this analysis is shown in Table 1.

Table 1. Classification based on parts' size. Source: own elaboration.

\begin{tabular}{cc}
\hline Dimensions $(\mathrm{mm})$ & Size \\
\hline$<100 \times 75 \times 75$ & $\mathrm{~A}$ \\
$>100 \times 75 \times 75$ and $<150 \times 100 \times 100$ & $\mathrm{~B}$ \\
$>150 \times 100 \times 100$ and $<250 \times 200 \times 200$ & $\mathrm{C}$ \\
$>250 \times 200 \times 200$ and $<350 \times 250 \times 250$ & $\mathrm{D}$ \\
$>350 \times 250 \times 250$ and $<500 \times 350 \times 350$ & E \\
$>500 \times 350 \times 350$ & F \\
\hline
\end{tabular}

However, after the first calculations, it was realized that the size, as an independent variable, was not really required, as the cost estimations based on the volume and the density of the parts were even more consistent and simpler to obtain.

\section{Results}

\subsection{Overview}

Industrial implementation of AM techniques to manufacture parts that up to now were almost exclusively formed using "traditional" methods would enable new features and possibilities for what is normally termed " 4.0 industry". Causality would, however, run both ways. The interconnection of devices, computers, tools, etc., that constitute the cyber physical systems (CPS) at the core of the 4.0 connected industry could boost the performance of both the individual AM machines and the overall operational systems. The significance of this synergic mutual reinforcement between AM and 4.0 industry has been highlighted by several authors [4,31,32].

There is also a growing consensus on the relevance of the influence and impact on social and environmental dimensions of these AM-deployment-related changes. This aspect should be considered throughout the complete life cycle of the industrial products, from design process to the EOL (end of life) phase, as highlighted at [21] and [31]. At [32], the analysis performed regarding the future projection of 34 key impacts derived from the adoption of AM techniques clearly shows that some soft social dimensions become absolutely critical. Especially focused on after sales activities of automotive sector, [29] also describes the most important aspects of these social impacts. Taking into consideration that for some countries like Spain, the SMEs' contribution to GDP is very important, it is interesting to consider, as [19] remarks, that the adoption of AM techniques might foster SME's competitiveness against larger firms. In short, there seems to be some consensus on the fact that the implementation of 
AM techniques at industrial sectors, as shown in [4], might contribute to improve health and social wellbeing, decrease physical hazards, and create wealth.

Even though a substantial part of the quantitative research in this paper is focused on the economic and business potential of AM, the overall approach taken holistically encompasses the various dimensions of sustainability. Economic viability is considered a precondition for the adoption of a new approach such as AM and is thus analyzed first. The potential impact of AM's adoption on other dimensions is however deemed critical, particularly because of the total size of global operations (design, production, distribution, service, and end of life processes) for an industrial sector like the automobile industry. Thus, the results will be presented from two perspectives: the economic and the sustainability perspective.

The results obtained through this methodology are representative from a local point of view (Iberian Peninsula), and allow comparisons, both for the brand and for the rest of the stakeholders (mainly authorized and independent dealers and final customers). While the current distribution model (Figure 3) has been used with slight modifications for a long time, the impact of European distribution regulations [28] have led to a large surge in competition and, consequently, to an important decrease in turnover for the manufacturers $[9,29]$. The new alternative SCM model that AM could enable (Figure 4) would have several important consequences for all stakeholders involved in the after-sales business. A key consequence would be the decentralization of production, making it easier for any supplier specialized in AM to manufacture parts from the original drawings or even from scans.

\subsection{Economic Perspective}

As already detailed in previous sections, for each part included in the analysis, the PNC (product number code), annual sales, dimensions (length $\times$ width $\times$ height), weight, country of origin, and the official retail price (for the Iberian market, fixed directly by the brand) are known. These data items are used as inputs for the AM cost estimation model.

For the analyzed case, most of the parts have their manufacturing origin in continents other than Europe, as only $11.49 \%$ of the analyzed items are produced there, spanning six different countries. "Continent I" encompasses 20 producing countries and accounts for $5.98 \%$ of the parts. Most relevant for the data being analyzed is "Continent II", comprising eight producing countries that manufacture $82.51 \%$ of the parts. This fact greatly conditions environmental impact, logistical costs, and delivery times, and also conditions in an important way the retail prices. It is obvious that, depending on the specific circumstances of the brand being analyzed and/or market circumstances, the situation would vary and, with it, the break-even point or the incentives for any given component to be manufactured using additive manufacturing.

Independently of the economic and environmental attractiveness of its manufacturing through AM, Table 2 shows the breakdown for the case study parts between those whose additive manufacturing would be technologically feasible and those for which it would not (e.g., assemblies, standardized parts such as seals, bearings, high precision parts). It is worth highlighting that, if this same analysis had been carried out only a decade ago, the results would have been very different, as the technology available at that time would not have allowed the manufacturing of many of the parts whose manufacturing is currently feasible.

Table 2. Viability of additive manufacturing for the parts of the case study. Source: own elaboration.

\begin{tabular}{ccccc}
\hline Viable with AM & PNC & \% PNC & Parts & \% Parts \\
\hline YES & 10,403 & $80.2 \%$ & 65,615 & $60.3 \%$ \\
NO & 2564 & $19.8 \%$ & 43,110 & $39.7 \%$ \\
Total & 12,967 & $1000 \%$ & 108,725 & $100.0 \%$ \\
\hline
\end{tabular}

Assuming that the most appropriate additive manufacturing technology is considered while analyzing which parts that can be manufactured by AM (Table 2), the results for the case study are 
shown in Table 3 (acronyms: direct deposition (DD), direct metal laser sintering (DMLS), electron beam melting (EBM), material jetting (MJ), selective laser sintering (SLS), stereolithography (SLA)).

Table 3. Quantitative detail of the parts that have been analyzed, based on low complexity and low sales volumes. Source: own elaboration.

\begin{tabular}{ccccccc}
\hline AM Technology & $\mathbf{5}$ & $\mathbf{6}$ to $\mathbf{1 0}$ & Parts & $\mathbf{\leq 5}$ & $\mathbf{6}$ to $\mathbf{1 0}$ & PNCs \\
\hline Binder Jetting & 329 & 100 & 429 & 152 & 13 & 165 \\
DD & 239 & 112 & 351 & 127 & 16 & 143 \\
DMLS & 807 & 352 & 1159 & 428 & 45 & 473 \\
EBM & 331 & 209 & 540 & 180 & 28 & 208 \\
Mat. Extrusion & 870 & 423 & 1293 & 442 & 57 & 499 \\
Mat. Jetting & 445 & 224 & 669 & 231 & 30 & 261 \\
Sheet Lam. & 125 & 71 & 196 & 58 & 10 & 68 \\
SLS & 926 & 397 & 1323 & 480 & 53 & 533 \\
Stereolithography & 509 & 211 & 720 & 286 & 26 & 312 \\
\hline
\end{tabular}

Once all the technological aspects have been explored, it is time to analyze the attractiveness from the business point of view of applying AM to each part. As previously discussed, this entails the estimation, with the proposed model (after calibrating and validating it through the RFPs), of the AM-based manufacturing cost for the part and its comparison with the brand-supplied current cost based on traditional processes. For this purpose, the parts that have been selected are those with low shape and structural complexity, with low sales volumes, and with low total density. Table 2 shows a summary of the set of parts that will be analyzed in detail from the economic point of view.

The key result to obtain from this analysis, within the economical perspective, is whether it would be profitable, and, if so, up to what extent, to start using AM in this target subset of their current spare parts. This is calculated by comparing the estimated AM-based production cost with the current, brand-supplied cost, expressing the difference as a percentage of the existing ESRPs and weighting it according to the part's sales volume. Figure 6 shows a summarized schema of the analysis that has been performed.

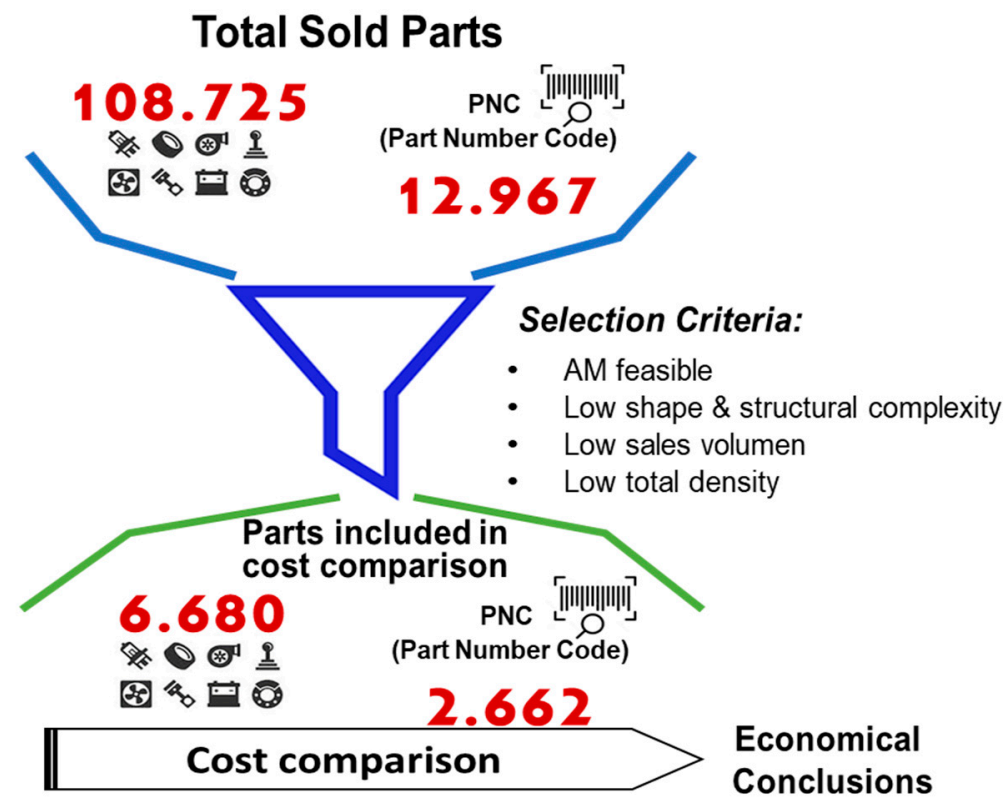

Figure 6. Summarized scheme of the economic analysis.

In this case study, and always considering "ceteris paribus", the analysis reveals that, under the hypotheses set out in the previous sections (focusing on parts with low difficulty and low sales): 
- The brand could increase its profit by $3.82 \%$ of the turnover associated with these pieces, which is equivalent to an increase of $15.12 \%$ over its margin with the traditional manufacturing and distribution model.

\subsection{Sustainability Perspective}

Continuing with the quantitative analysis, the analysis further reveals, under the same hypotheses, the following sustainability-related results:

- By decreasing the final number of manufactured components, the reduction in total material used can be estimated at $12.3 \%$.

- Considering the important decrease in transportation needs, the associated energy saving (and consequently $\mathrm{CO}_{2}$ and rest of pollutants), could reach 9.2\%. And this $\mathrm{CO}_{2}$ reduction, given the current regulation over the maximum emissions of pollutants that are allowed for the automotive manufacturers' car sales, could in turn become, in a quite short time horizon, a very important economical aspect.

As for the qualitative implications, the automotive sector, even in its "as is" situation, is one of the industrial activities that involves more stakeholders. When AM technologies are applied to this business, the number of interested and affected stakeholders greatly increases. However, this fact does not necessarily mean that the situation gets more complicated. With the current situation of the automotive sector, all the different stages of the life cycle are very strong and stable. From the design process, to the after sales and maintenance operations, going through all the other steps (production, warehousing and inventories, distribution, sales, etc.) it is difficult and expensive to change any of the parts of the vehicle, as it would automatically mean the reengineering of important processes, the scrapping of old parts, etc.

From the above, it automatically follows that it is very important not to introduce changes into the whole value and supply chains, and, in case it is imperative to do so, it should be done from a holistic perspective, analyzing at the same time all the involved processes [13].

With the introduction of AM manufacturing techniques, a wide variety of alternative approaches would become feasible within the automotive sector, making it much easier to implement minor parts' modifications, redesigns, etc. It would also allow a complete revolution of the sector in the forthcoming years from the concept design phase, as AM enables designs, assemblies, and layouts that are nearly impossible to implement with the more conventional forming processes. Additionally, this aspect is particularly critical when talking about metal additive manufacturing (MAM), with great importance in both life cycle engineering and life cycle assessment (LCE and LCA), as analyzed in [33].

If the whole lifecycle is considered in conjunction with AM possibilities, some key aspects like reuse, recycling, and reconditioning, that up to now have been considered only marginally, become central to the new model, thus greatly improving its sustainability potential [21] and the advantages for what is called the "3P"(people, planet, and profit).

Other aspects that should be considered when speaking about complex machines like vehicles, and the possibility to use AM techniques to manufacture parts, are everything that concerns to 4.0-industry-related aspects and possibilities. When considering the situation from a global point of view, including all the main stakeholders, [21], certain aspects like self-service or self-maintenance, with the vehicle itself acting as a "self-trouble shooter", "self-ordering" the needed part, and "self-booking" the appointment for the repair shop, are no longer unfeasible. These innovations could in turn unleash a wave of innovation that would allow the optimization in the use of most of the resources.

\section{Discussion}

It is still too early to have a clear picture regarding all the potential impacts that the use of AM techniques could have for the industry in general, and for the automotive sector spare parts distribution in particular, as there are still a lot of aspects that must be developed, improved, or even discovered. 
One of the first facts to be acknowledged is that, among the different techniques that are grouped under the AM denomination, the differences are enormous. For example, the energy consumption (one of the main costs of AM techniques) is radically different for electron beam melting [34] than for laser selective melting [5], and even for the same techniques, the operating and cost differences when using different types of material preparation, working and printing parameters, and parts' positioning and orientation are very significant.

The implications and potential benefits of applying AM in specialized areas or from particular perspectives have been analyzed in various publications. For instance, nearly nobody currently disputes that AM is the best option for rapid prototyping $[17,26]$ or for very specific niche applications like those analyzed in [19]. Specifically from a social perspective, a comprehensive and highly relevant survey conducted for a representative sample of AM-related professionals is presented in [4]. It identifies a total of 28 fundamental factors enabled by the use of AM techniques that are closely related to critical aspects of modern society, such as working conditions and health. It suggests that AM has the potential to add social value to the adopting companies and improve their corporate social responsibility.

However, there is a lack of published studies regarding the viability of applying AM in large operational activities, from an encompassing business point of view, and supported by real data, as in the study described in this paper.

\section{Conclusions}

As discussed in the introduction and in the analysis of the research gap, the aspects that have up to now been most thoroughly studied in relation to the application of AM to industry are those related to technology (machines, materials, etc.), but there has been limited research regarding its direct impact on business models in real cases from a sustainable supply chain management (SSCM) perspective.

In the present paper, in line with the stated objectives, a more global approach has been conducted, and the main contributions to the AM industrial applications investigation field could be summarized as follows:

- The potential quantitative (KPI-based) and qualitative (business and organizational model transformation) economic, social, and environmental impact of AM techniques in the industrial sector has been analyzed, rather than adopting a single approach or perspective.

- Rather than focusing on a single AM technique, the analysis encompasses the most widely used techniques (by pairing each analyzed part with the most appropriate technique before performing the analysis), thus providing a more global perspective of AM's applicability from a business point of view.

- Research has been conducted within the automotive sector, which, while being as technologyintensive as, for example, the aeronautical sector, is also highly competitive and involves a large number of players, much more so than the aeronautical sector. Furthermore, it focuses on the after-sales business, thus casting light on a promising but scarcely explored potential avenue for introducing AM into the strategic automotive industry.

- An analytical methodology has been presented to evaluate the foreseeable impact of the adoption of a new AM-based model of spare parts' manufacturing and distribution processes that can be easily extrapolated to other automotive companies or industrial sectors. It is also flexible enough to allow it to evolve and adjust to eventual AM-related changes in the future.

- As this study case is based on a large-scale set of real data, it could reassure business managers of the actual applicability in their own environments of its conclusions (the current viability of embracing properly targeted adoption of AM techniques in areas beyond their traditional niches).

Therefore, research projects such as this, which analyze the potential impact of AM in sectors as important for the world's GDP as the automotive industry, from both an economic and a sustainability perspective, are likely to become increasingly common. It shows that even at the present time, when the industrial application of AM is still incipient, and in a limited territorial and market environment such 
as the Iberian Peninsula, it would be possible to improve the industrial margin of automobile spare parts business activities, while decreasing the environmental impact of its industrial associated activities. Among the limitations of the current study, the following can be highlighted:

- Being case-study based, its extrapolability to other geographical areas and industries must be verified.

- As discussed in the Materials and Methods section, several simplifying hypotheses have been assumed (namely, selling prices and volumes for spare parts are considered invariant), which could be further explored.

- In-depth analysis of some of the identified risks (intellectual property, liability) has been considered beyond the scope of this research.

Lastly, apart from further analyzing the abovementioned limitations, three main future lines of research have been identified:

- The improvement of the models for cost estimation, considering aspects related to service quality (e.g., VOR orders, out of route vehicles, and repair deadlines).

- Contemplating within the study the option of repairing the parts through AM (rather than completely replacing the components, considering the repair of the deteriorated one, thus enabling circularity, [20]).

- The scaling of the proposed model to the global market in which today's automobile groups operate.

Author Contributions: Conceptualization: L.I.-S., J.M.-B., J.I.O.-G., and A.D.-H.; methodology: L.I.-S., J.M.-B., J.I.O.-G., and A.D.-H.; validation: L.I.-S. and A.D.-H.; formal analysis: L.I.-S., J.M.-B., J.I.O.-G., and A.D.-H.; investigation: L.I.-S., J.M.-B., J.I.O.-G., and A.D.-H.; resources: L.I.-S. and J.M.-B.; data curation: L.I.-S., J.M.-B., J.I.O.-G., and A.D.-H.; writing-original draft preparation: L.I.-S., J.M.-B., J.I.O.-G., and A.D.-H.; writing-review and editing: L.I.-S., J.M.-B., J.I.O.-G., and A.D.-H.; visualization: L.I.-S., J.M.-B., J.I.O.-G., and A.D.-H.; supervision: L.I.-S., J.M.-B., J.I.O.-G., and A.D.-H.; project administration: L.I.-S., J.M.-B., J.I.O.-G., and A.D.-H. All authors have read and agreed to the published version of the manuscript.

Funding: This research received no external funding

Conflicts of Interest: The authors declare no conflict of interest.

\section{References}

1. Wang, S.; Wan, J.; Zhang, D.; Li, D.; Zhang, C. Towards smart factory for industry 4.0: A self-organized multi-agent system with big data based feedback and coordination. Comput. Netw. 2016, 101, 158-168. [CrossRef]

2. Johnson, D.; Bogers, M.; Hadar, R.; Bilberg, A.; Jiang, R.; Kleer, R.; Piller, F.T.; Gebhardt Andreas, J.-S.H.; Ålgårdh, J.; Strondl, A.; et al. 3D Printing The Next Revolution in Industrial Manufacturing. J. Ind. Ecol. 2017, 237, 1-10. [CrossRef]

3. Wohlers Associates. Wohler's Report 2018; Wohlers Associates: Fort Collins, CO, USA, 2018.

4. Matos, F.; Godina, R.; Jacinto, C.; Carvalho, H.; Ribeiro, I.; Peças, P. Additive manufacturing: Exploring the social changes and impacts. Sustainability 2019, 11, 3757. [CrossRef]

5. Faludi, J.; Baumers, M.; Maskery, I.; Hague, R. Environmental Impacts of Selective Laser Melting: Do Printer, Powder, Or Power Dominate? J. Ind. Ecol. 2017, 21, S144-S156. [CrossRef]

6. Kiene, O. How the automotive industry will benefit from digitalization. Automobilwoche 2015. Available online: https://www.accenture.com/_acnmedia/Accenture/Conversion-Assets/DotCom/ Documents/Global/PDF/Industries_18/Accenture-Automobilwoche-Supplement-2015-English.pdf (accessed on 10 December 2019).

7. Becker, D. KPMG's 20th Global Automotive Executive Survey 2019; KPMG: Amstelveen, The Netherlands, 2019.

8. Mumith, A.; Thomas, M.; Shah, Z.; Coathup, M.; Blunn, G. Additive manufacturing current concepts, future trends. Bone Jt. J. 2018, 100B, 455-460. [CrossRef] [PubMed]

9. Gissler, A.; Mueller, J. Automotive After Sales 2015. Automot. Insight Arthur D. Little Special Report. Available online: https:/www.adlittle.com/sites/default/files/viewpoints/AMG_Automotive_after_sales_ 2015_01.pdf. (accessed on 10 December 2019). 
10. U.S. Navy. ProQuest LLC MILITARY Manufacturing of F-18 Aviation Parts Sought; Targeted News Service: Washington, DC, USA, 2011; pp. 1-2.

11. Khajavi, S.H.; Partanen, J.; Holmström, J. Additive manufacturing in the spare parts supply chain. Comput. Ind. 2014, 65, 50-63. [CrossRef]

12. 3D Hubs. 3D Hubs Digital Manufacturing Trends. 3D Hubs. Available online: https://www.3dhubs.com/ blog/digital-manufacturing-trends-q3-2018/ (accessed on 10 December 2019).

13. Swerea Swedish Research State-of-the-art for Additive Manufacturing of Metals Executive Summary. Available online: https://www.metalliskamaterial.se/globalassets/3-forskning/rapporter/2016-03898---stateof-the-art-for-additive-manufacturing-of-metals-2_1.pdf (accessed on 10 December 2019).

14. Koff, W.; Gustafson, P. 3D Printing and the Future of Manufacturing. CSC Lead. Edge Forum 2012, 1-11. [CrossRef]

15. Turk, Ž.; Klinc, R. Potentials of Blockchain Technology for Construction Management. Procedia Eng. 2017, 196, 638-645. [CrossRef]

16. Reeves, P.; Mendis, D. The Current Status and Impact of 3D Printing Within the Industrial Sector: An Analysis of Six Case Studies; Bournemouth University: Dorset, UK, 2015; ISBN 978-1-908908-86-5.

17. Niaki, M.K.; Nonino, F.; Palombi, G.; Torabi, S.A. Economic sustainability of additive manufacturing: Contextual factors driving its performance in rapid prototyping. J. Manuf. Technol. Manag. 2019, 30, 353-365. [CrossRef]

18. Savolainen, J.; Collan, M. How Additive Manufacturing Technology Changes Business Models?-Review of Literature. Addit. Manuf. 2020, 32, 101070. [CrossRef]

19. González-Varona, J.M.; Poza, D.; Acebes, F.; Villafáñez, F.; Pajares, J.; López-Paredes, A. New business models for sustainable spare parts logistics: A case study. Sustainability 2020, 12, 3071. [CrossRef]

20. Turner, C.; Moreno, M.; Mondini, L.; Salonitis, K.; Charnley, F.; Tiwari, A.; Hutabarat, W. Sustainable production in a circular economy: A business model for re-distributed manufacturing. Sustainability 2019, 11, 4291. [CrossRef]

21. Ribeiro, I.; Matos, F.; Jacinto, C.; Salman, H.; Cardeal, G.; Carvalho, H.; Godina, R.; Peças, P. Framework for life cycle sustainability assessment of additive manufacturing. Sustainability 2020, 12, 929. [CrossRef]

22. Office of Transportation and Machinery U.S. Department of Commerce. On the Road: U.S. Automotive Parts Industry Annual Assessment. Available online: https:/legacy.trade.gov/td/otm/assets/auto/2011Parts.pdf (accessed on 10 December 2019).

23. Hernandez Korner, M.E.; Lambán, M.P.; Albajez, J.A.; Santolaria, J.; Ng Corrales, L.D.C.; Royo, J. Systematic Literature Review: Integration of Additive Manufacturing and Industry 4.0. Metals 2020, 10, 1061. [CrossRef]

24. Son, Y.K. A cost estimation model for advanced manufacturing systems. Int. J. Prod. Res. 1991, $29,441-452$. [CrossRef]

25. Crane, J.; Crestani, R.; Cotteleer, M. 3D Opportunity for End-Use Products: Additive Manufacturing Builds a Better Future; Deloitte Univniversity Press: London, UK, 2014; p. 16.

26. Gebhardt, A. The Management of Additive Manufacturing. J. Clin. Orthop. Trauma 2018, 2, 380-386.

27. Niaki, M.K.; Torabi, S.A.; Nonino, F. Why manufacturers adopt additive manufacturing technologies: The role of sustainability. J. Clean. Prod. 2019, 222, 381-392. [CrossRef]

28. UE Reglamento (UE) no 461/2010: Aplicación del artículo 101(3) del Tratado de Funcionamiento de la Unión Europea a determinadas categorías de acuerdos verticales y prácticas concertadas en el sector de los vehículos de motor. Available online: https://www.boe.es/doue/2010/129/L00052-00057.pdf. (accessed on 10 December 2019).

29. Lešková, A. Tendency of Customizing Aftersales Services to Support Agility in Automotive Business. Littera Scr. 2015, 8, 28-39.

30. Wohlers Associates. Wholers Report 2016; Wohlers Associates: Fort Collins, CO, USA, 2016; ISBN 978-0-9913332-2-6.

31. Godina, R.; Matos, F.; Ferreira, B.T.; Carvalho, H. Impact Assessment of Additive Manufacturing on Sustainable Business Models in Industry 4.0 Context. Sustainability 2020, 12, 7066. [CrossRef]

32. Bokrantz, J.; Skoogh, A.; Berlin, C.; Stahre, J. Maintenance in digitalised manufacturing: Delphi-based scenarios for 2030. Int. J. Prod. Econ. 2017, 191, 154-169. [CrossRef] 
33. Daraban, A.E.O.; Negrea, C.S.; Artimon, F.G.P.; Angelescu, D.; Popan, G.; Gheorghe, S.I.; Gheorghe, M. A deep look at metal additive manufacturing recycling and use tools for sustainability performance. Sustainability 2019, 11, 5494. [CrossRef]

34. Baumers, M.; Tuck, C.; Wildman, R.; Ashcroft, I.; Hague, R. Shape Complexity and Process Energy Consumption in Electron Beam Melting: A Case of Something for Nothing in Additive Manufacturing? J. Ind. Ecol. 2017, 21, S157-S167. [CrossRef]

Publisher's Note: MDPI stays neutral with regard to jurisdictional claims in published maps and institutional affiliations.

(C) 2020 by the authors. Licensee MDPI, Basel, Switzerland. This article is an open access article distributed under the terms and conditions of the Creative Commons Attribution (CC BY) license (http://creativecommons.org/licenses/by/4.0/). 